\title{
Legal challenges of emergency risk management in the context of Eurasian integration (Armenian case)
}

\author{
Armen Harutyunyan ${ }^{1, *}$, Vahe Davtyan ${ }^{2}$ \\ ${ }^{1}$ Crisis Management State Academy of the Ministry of Emergency Situations of the Republic of \\ Armenia, 0040, Acharyan st., 1, Yerevan, Armenia \\ ${ }^{2}$ Russian-Armenian University, 0051, H. Emin st., 123, Yerevan, Armenia
}

\begin{abstract}
In a rapidly changing world, the volume, quality and geography of emerging phenomena are also changing. Despite the fact that about 110 types of known natural hazards are specific to Armenia, it seemed that we already have enough experience to withstand various emergencies, pandemics, however, Covid-19 showed that not only The Republic of Armenia, but a number of other advanced states were not ready to face the pandemic that caused many deaths and economic crises. The member states of Eurasian Economic Union (EAEU) are no exception among these states. In Armenia, more than 200000 people were infected by Covid-19 for about 1.5 years, as a result of which for about thousands of people died. The presented numbers already show, that in a republic with a small population, the healthcare system objectively appeared in a crisis situation and isn't able to respond operatively in such situations. The same situation has been registered in the rest EAEU member states, as a result of which in the rest EAEU member states also thousands of people died. In this context, the issues of food security, as well as the implementation of large strategic infrastructure projects during pandemic, are of particular importance.
\end{abstract}

\section{Introduction}

Pandemic showed, that especially post-Soviet/EAEU states are not ready to face the challenges effectively in an emergency situation, which could reduce the number of both infected and, of course, of deaths [1].

It is important to mention that till today there haven't been developed relevant legislative regulations in the EAEU states and especially in the Republic of Armenia, which would allow in similar situations to quickly bring the state to readiness to use the tools typical to the emergency regime, as a result of which it would be possible to carry out better prevention, response, and elimination of consequences $[2,13]$.

As an example we can show a fact, that there is no institute of emergency situations provided by the legislation of the Republic of Armenia, the scope of powers of the authorized bodies in case of pandemics or similar emergency situations, i.e. the Ministry of Emergency Situations and the supporting agencies, is not specified. There are even no maps of

\footnotetext{
${ }^{*}$ Corresponding author: armenh88@mail.ru
} 
emergency situations in the Republic of Armenia, which would help to organize the process of forecasting, prevention and response of emergency situations operatively. This gap touches upon not only the narrow issues concerning the prevention and response of emergency situations, but also the steady development of the political and state organs in the condition of emergency situations. From this point of view, in contrast with the recognized states of the EAEU, in the Republic of Artsakh the concept of emergency situations is established on the constitutional level. Moreover, since the political institute of the Republic of Artsakh was formed in the conditions of crisis situations, she has an experience on organizing political and economic processes in the conditions of emergency [2].

As a result of the unsolved problem, it became necessary to study thoroughly the individual and joint policies pursued by the EAEU member states during the fight against the pandemic, their legislative and technical regulations, which will allow to synchronize the work of the EAEU member statesin similar situationsin the future, and to raise the level and quality within member states[4].

Taking into account, that effective emergency risk management mechanisms are primarily related to four main areas, the main goals and problems of the study are achieved in their directions:

- Improvement of the legal framework,

- creation of the necessary database and provision of its further development,

- selection of methods for determining possible consequences,

- modeling of disaster risk management.

Improvement of legal framework has two major aims:

- clarification of obligations and responsibilities for the actors involved in the disaster risk management process,

- legal support of financial mechanisms necessary for disaster risk reduction [5].

\section{Methodology}

The research is based on a complex method, which includes the analysis of scientific and normative literature. Comparative, historical, systemic, statistical, field research methods are used in the research. The following approaches are used to solve the established problems: institutional, legal-political, geopolitical, sociological, value system, etc. Quantitative and qualitative content analysis and monitoring methods are used, which allow to build the empirical base of the research. The use of the data science software is especially important in the latter case.

The research involves the integration of different scientific directions (law, political management, technical sciences, crisis management, geology), including with the use of computer and information technologies (geoinformation technologies, database creation). In this context, the interdisciplinary nature of the research is obvious. Moreover, the developed tools and concepts can be applied in other areas as well.

\section{Results}

In the EAEU, particularly in the Republic of Armenia, the legislative framework for the whole sphere of emergency situations are to be studied, problems are to be identified, packages of legislative initiatives are to be developed, by which the scope of concrete authorities and activities of all - state and private organizations, individuals, should be defined.It is necessary to create emergency maps, which will allow to organize more operatively the work on monitoring, prevention, response and elimination of consequences. Monitoring software systems will enable to do researches and analysis, the results of which 
will allow to make both environmental and social-economic forecasts in case of various emergencies, operatively and beforehand to assess possible effects of this or that emergency situation and epidemics on the environment, economy, and on the quality of life of the population, to develop ways to mitigate those consequences, to draw short-term and longterm optimal plans for eliminating the consequences $[6,7]$.

The results andsystematized archival data can be used by the authorized bodies of Armenia and the other EAEU Member States and, particularly, by the Ministries of Emergency Situations, to make appropriate legislative amendments and to use the maps, which should be created, for disaster risk management.

The implementation of the project tasks involves the integration of different scientific directions (law, political management, technical sciences, crisis management, geology), including the use of computer and information technologies (geoinformation technologies, database creation).In this context, the interdisciplinary nature of the research problem [1].

Taking into account the fact that the chosen topic includes the issues of emergency risk management in the EAEU member states, and particularly in the Republic of Armenia, it is expected that the general results will be relevant, especially for the relevant scientific and state structures of the EAEU member states, considering the fact of being the part of one supranational organization and the similarities of actions taken by the Republic of Armenia and those countries, targeted to overcome the emergency situations and especially the pandemic. Moreover, throughout the whole period of the fight against the pandemic, the EAEU member states have been guided by both the World Health Organization (WHO) and the EAEU Advisory Guidelines.

The above mentioned supposes, that the results of the study can be useful for all EAEU member states in order to develop appropriate institutions and to create and develop tools, which aims to manage the risk of possible emergencies, and particularly to organize the fight against the pandemic effectively.

The results and systematized archival data can be used by the authorized bodies of Armenia and other EAEU Member States and, particularly, by the Ministries of Emergency Situations, to make appropriate legislative amendments and to use the maps, which should be created, for disaster risk management.

\section{Discussion}

The purpose of emergency situations risk management is to reduce the risk, which is implemented by a proper governmental body in a way of making a decision and implementing it [8]. The key indicator for decision making in order to reduce risk is the risk assessment, which is the result of the risk assessment. And the risk assessment is related to danger assessment, assessment of possible consequences of those dangers, as well as the skills required for risk assessment (specialists, knowledge, risk assessment organizations or departments, monitoring units, availability of risk assessment methods). Making and implementing risk reduction management decisions is related to the elimination of hazards or their mitigation (impact), or the reduction of potential consequences (i.e., mitigation of vulnerabilities to hazards), as well as the corresponding capabilities. In this case capabilities include knowledge, institutional, technical, financial, and monitoring and other skills. Consequently, the effects of the risk management are focused on the danger, vulnerability, and are related to the capabilities of the management system. If the capabilities of the management system are small, the impacts of management on hazards and vulnerabilities are ineffective. Consequently, management influences should be aimed to increasing the capacity of the system as well [9].

Two important areas are studied in our research out of the 12 vulnerability reduction guidelines: 
- creation of legislative framework and ensuring its development;

- creation of a crisis management system and ensuring its development.

The development and implementation of modern mechanisms for disaster risk management are conditioned by these two directions.

The discovery and research of the economic security component is especially important in the context of this topic [10]. Particularly, the termination of cooperation between Armenia and the other EAEU member states during the pandemic, due to paralysis of transport systems and, as a result, obstacles to the import and export of essential goods, which is a key component of food security [11], will be studied in the project. The experience and issues of food security in Armenia and the EAEU member states are assessed, including the legal framework for policy synchronization and efficiency. A special attention should be paid to the new challenges of ensuring Armenia's food security because of the loss of agricultural lands (95 thousand hectares) in a result of the Artsakh war, taking into account, for example, the cessation of imports of wheat, grain and other agricultural products from Artsakh. (It is enough to mention that up to 600 thousand tons of wheat is consumed annually in Armenia and Artsakh, about 30\% of which was produced in Artsakh) [12].

At the same time, the steps of Armenia and the EAEU member states aimed to the uninterrupted implementation of large strategic infrastructure projects in the conditions of a pandemic should stay in focus. Particularly, in this context, special attention should be paid to energy and transport infrastructure, taking into account the suspension or postponement of the implementation of a number of projects in Armenia because of Covid-19 (Armenian NPP, Yerevan Thermal Power Plant, Iran-Armenia 3rd High-Voltage Air Line) [12]. Taking into account the importance of these projects from the point of Armenia's challenges to integration into the EAEU common energy markets, it is necessary to study the experience of crisis management of the energy transport systems of the EAEU member states and to synchronize steps to neutralize further risks $[14,15]$. Thus, we are dealing with the problems of ensuring the country's energy transport security, the solution of which is especially important, taking into account the deep geopolitical and geo-economic transformations taking place in the region.

As it is already mentioned, effective disaster risk management mechanisms are related to four main areas:

- improvement of legal framework,

- creation of necessary database and ensuring of its further development,

- selection of methods for determining possible consequences,

- modeling of disaster risk management.

The improvement of legal framework supposes achieving following goals:

- clarification of obligations and responsibilities for the actors involved in the disaster risk management process,

- legal support of the financial mechanisms necessary for disaster risk reduction.

Creating of the necessary databases is associated with the components by which the risk is conditioned. These are databases of hazards, vulnerabilities and capabilities. Hazard databases include hazard map databases, historical hazard and disaster databases concerning the same area. The latter are, in fact, statistics that give an opportunity to verify the information on the origin of hazards and the probability of disasters. It should be noted that the development of hazard maps should also include options for impacting different intensities of the same hazard. This will help to determine the zones of influence, and, consequently, to calculate the use of forces and means from the areas adjacent to those zones [16].

Capacity databases include databases on knowledge capacity (including institutional capacity), technical capacity (from small mechanization to heavy equipment), financial and other capacities. 
In order to create such databases, it is necessary to develop the indicators of their creation, the mechanisms of identification (identification) to turn them into blocks, and generally, the mechanisms of database identification, as different actors have different abilities.

Vulnerable element databases include various subsystems (buildings, structures, occupants with different vulnerabilities, dangerous enterprises, engineering structures, engineering networks, technical and technological elements, etc.).

The choice of methods for determining possible effects is related to the diversity of those effects, and consequently to the parameters with different dimensions. The results can be human casualties, injuries, homelessness, collapsed houses, structures, buildings, destroyed dangerous objects (secondary hazards), broken engineering networks (canals, highways, water supply, gas supply, sewer, electricity supply, etc.). The potential impact assessment process complexity is conditioned with the mentioned above.

Risk management modeling is related to the introduction of a unified risk assessment methodology, the development and implementation of digital maps, and decision-making modeling [17].

Digitized maps should include different layers. For example: dangers, buildings, structures, water supply, gas supply, sewerage, road networks, population maps, etc. The risk can be assessed by layer-by-layer comparison of these maps. Their existence can dramatically increase the effectiveness of decisions concerning the risk reduction.

\section{Conclusion}

The problems of anti-crisis management are crucial in modern public administration, which is mainly due to the spread of waves of a pandemic, which creates risks and threats to national security for all countries. These risks and threats should be considered from an interdisciplinary perspective in order to identify their specificity with the development of methods to overcome them.

Disaster risk management cannot be the monopoly of any institution in the country. The process of disaster risk management requires the participation of all structures of the country (regardless of the type of organization), as well as international organizations. It requires relevant ongoing scientific and practical research, the contribution of mechanisms adopted as a result of it, mechanisms, the whole of which is accepted to be called a national disaster risk reduction environment, which will be applicable both for the Republic of Armenia and the other EAEU member states.

\section{References}

1. S. Semerikov, S. Chukharev, S. Sakhno, A. Striuk, A. Iatsyshyn, S. Klimov, V. Osadchyi, T. Vakaliuk, P. Nechypurenko, O. Bondarenko, H. Danylchuk, Our sustainable pandemic future, ICSF 2021, Web of Conferences, 280, 00001 (2021). Access mode: https://doi.org/10.1051/e3sconf/202128000001

2. A. Harutyunyan, Parliamentary-presidential elections in the Republic of Artsakh in an emergency situation of international importance, Crisis Management and Technology, 1, 13-21(2020)

3. A. Malinovsky, D. Osina, E. Trikoz, TPACEE-2019, Web of Conferences, 164, 11039 (2020). Access mode: https://doi.org/10.1051/e3sconf/202016411039

4. A. Vorona, L. Kopteva, A. Trushevskaya, The Eurasian economic union: trends and prospects for development in digital economy, ITSE-2020. Web of Conferences, 210, 13025 (2020). Access mode: https://doi.org/10.1051/e3sconf/202021013025 
5. V. Kasyanov, V. Danilchenko, V. Amelin, V. Tolmacheva, Environmental risk management. Forecasting and modeling of emergency risk management situations, IPICSE-2018. MATEC Web of Conferences, 251, 06030 (2018). Access mode: https://doi.org/10.1051/matecconf/201825106030

6. V. Borkovskaya, E. Degaev, I. Burkova, Environmental economic model of risk management and costs in the framework of the quality management system, MATEC Web of Conferences, 193 (2018). Access mode: https://doi.org/10.1051/matecconf/201819305027

7. E. Lyapuntsova, Yu. Belozerova, I. Drozdova, G. Afanas'ev, E. Okunkova, Entrepreneurial risks in the realities of the digital economy, IPICSE-2018. MATEC Web of Conferences, 251, 06032 (2018). Access mode: https://doi.org/10.1051/matecconf/201825106032

8. M. Berberova, Assessment of personnel actions in the most dangerous accidents, ENERGY-21 Web of Conferences, 209, 03007 (2020). Access mode: https://doi.org/10.1051/e3sconf/202020903007

9. K. Vichova, M. Hromada, The analysis of crisis management information system in the selected states, CSCC 2018. MATEC Web of Conferences, 210, 02025 (2018). Access mode: https://doi.org/10.1051/matecconf/201821002025

10. A. Litvinenko, G. Gioev, Yu. Gnezdilov, M. Podvoiskaya, A. Sidenko, Principles of ensuring economic security, IX Baltic Legal Forum 2020. Web of Conferences, 108, 03013 (2021). Access mode: https://doi.org/10.1051/shsconf/202110803013

11. S. Kurbatova, V. Vlasov, L. Aisner, Impact of risks and threats on the region's food supply in the context of import substitution, ICEPP-2020.Web of Conferences, 161 (2020). Access mode: https://doi.org/10.1051/ conf/ 202016101089

12. V. Davtyan, Problems of ensuring food security of unrecognized states (on the example of the Republic of Artsakh), Proceedings of the Southwest State University. Series: Economics, Sociology and Management, 11(1), 10-19 (2021)

13. A. Markarov, V. Davtyan, Socio-economic situation in Armenia during Covid-19 pandemic: impact of quarantine measures on the energy sector, Geo-economy of Energy, 4 (12), 59-76 (2020)

14. M. Lukmanova, D. Akhmetov, R. Sapanova, Risks of the formation of common gas and oil markets of the Eurasian Economic Union in modern conditions, BTSES-2020. Web of Conferences, 159, 02006 (2020). Access mode: https://doi.org/10.1051/e3sconf/202015902006

15. A. Gibadullin, V. Pulyaeva, Obstacles to the formation of a common electricity market of the Eurasian Economic Union, Energy Systems Research. Web of Conferences, 114, 02002 (2019). Access mode: https://doi.org/10.1051/e3sconf/201911402002

16. N. Azizat, W. M. Sabki Wan Omar, Assessment of three flood hazard mapping methods: A case Study of Perlis, CENVIRON 2017. Web of Conferences, 34, 02028 (2018). Access mode: https://doi.org/10.1051/e3sconf/20183402028

17. L. Wen-bing, Wang Jun, Wu You-fen, F. Xing-lai, Research on heterogeneous digital map resource query algorithm based on web services, ICAEER 2020. Web of Conferences, 194, 05001 (2020). Access mode: https://doi.org/10.1051/e3sconf/202019405001 